\title{
Elimination of Vector-borne Transmission of Chagas Disease
}

\author{
AC Silveira/ ${ }^{+}$, MC Vinhaes* \\ Panamerican Health Organization, Brazilian Office, Setor de Embaixadas Norte, Lote 19, 70800-400 Brasília, \\ DF, Brasil *Fundação Nacional de Saúde, Setor de Autarquias Sul, Quadra 4, Bloco N, 70058-902 Brasília, DF, \\ Brasil
}

The control of the vector-borne transmission of Chagas disease in Brazil was organized as a national program in 1975, when two large entomological and sero-epidemiological surveys were conducted in the country in order to identify areas at highest risk of transmission and to guide inerventions regarding the chemical treatment of domestic vectors of the disease. The authors present the baseline data gathered through these studies and compare them with more recent data. The evaluation performed shows that the transmission by Triatoma infestans is virtually interrupted and that the transmission by other native species of triatominae from different regions of the country is possibly very low. It is emphasized the need to maintain permanent actions of entomological surveillance in order to prevent recurrent transmission.

Key words: Chagas disease - control - Triatoma infestans - entomological surveillance

To start with, it is necessary to define precisely what is meant by elimination of the transmission. The attainable control levels of a disease depend on its vulnerability to available instruments, or the existing technology, as well as its epidemiology and our knowledge about it.

There are diseases for which complete eradication can be expected, meaning the definite interruption of the transmission. So it happened with smallpox and it is assumed to happen with poliomyelitis, basically as a result of the use of powerful intervention instruments. For other illnesses, the interruption of transmission can be envisaged in certain geographic areas and under certain epidemiological circumstances. For example, malaria transmission has been stoped in large areas, but it is still persistent in other regions where the transmission pattern is less favorable to the so called "strictly sanitary" control actions. The current understanding is that for such diseases, elimination can be set as a goal. This means that disease transmission could be interrupted in a limited or temporary scale, with a smaller or greater chance of being reinstated. Elimination requires, then, that a least some of the control activities be maintained over time (Tauil 1998). Finally, there are diseases for which the maximum attainable level is the re-

${ }^{+}$Corresponding author. Fax: +55-61-321.1922. E-mail: silveira@bra.ops-oms.org

Received 9 June 1999

Accepted 9 August 1999 duction of the transmission, or even the reduction of the risks of occurence of cases and deaths.

Since Chagas disease is originally enzootic, it cannot be included in the "eradicable diseases". The transmission will surely continue in the wilderness by the transference of Trypanosoma cruzi among reservoirs and vectors in natural ecotopes. Even accidental human infection can take place. Domiciliary transmission can also be reinstated from silvatic foci, provided the necessary conditions for this occurrence are maintained.

Therefore, on the basis of factual findings, Chagas disease is prone to be eliminated. This is true either for home transmission via vector or for other transmission mechanisms.

Even though chemical treatment of infested houses has been proven efficient since 1948 (Busvine \& Barnes 1947, Romaña \& Abalos 1948, Dias \& Pellegrino 1948), actions coping with the vector were systematized as a national program only in 1975. Between 1975 and 1980, two extensive epidemiological surveys were carried out in the country in order to update the existing information and to better determine the areas at risk of vector-borne transmission. Previous information came from scattered and non comparable studies, using different methodologies and techniques.

The serological survey was carried out through random sampling in rural areas of all Brazilian counties, except those located in the State of São Paulo, where regular control measures had been effective since the $60 \mathrm{~s}$. The national average prevalence rate of infection was $4.2 \%$, with a maximum state level of $8.8 \%$ in Minas Gerais and Rio Grande do Sul (Fig. 1) (Camargo et al. 1984). Some counties showed prevalence rates higher than $50 \%$ while 


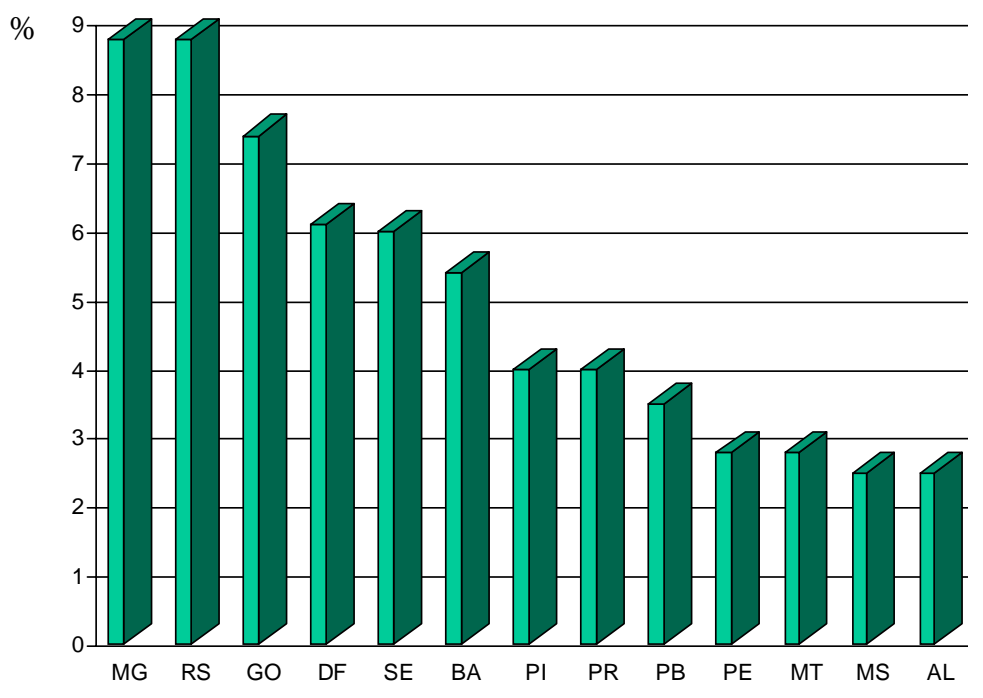

Source: GT-Programa de Controle da Doença de Chagas/CCDTV/DEOPE/FNS.

Fig. 1: Chagas infection prevalence in the states with risk of vector-borne transmission, Brazil, 1980.

in many others, specially in the northern region, no positive tests were found.

The large entomological survey demonstrated 17 vector species living in household environments, with varying degrees of colonization and natural infection. Five of those species were considered of special importance in regard to direct transmission of the disease to man: Triatoma infestans, $T$. brasiliensis, Panstrongylus megistus, $T$. pseudomaculata e T. sordida (Table I, Fig. 2) (Silveira et al. 1984).

With the exception of $T$. infestans which had been introduced in the country and is strictly domiciliated, the other species are native of different regions and are distributed according to specific geographical patterns. Thus, T. sordida is found in the mid-west as well as in areas of the southeastern and northeastearn regions where the

TABLE I

Triatominic survey. Species and positiveness, Brazil, 1975/1983

\begin{tabular}{lrrrr}
\hline \multirow{2}{*}{ Genus and species } & & \multicolumn{3}{c}{ No. of specimens } \\
\cline { 3 - 5 } & Captured & Examined & Positive & \% positiveness \\
\hline Triatoma sordida & 189,260 & 97,595 & 2,222 & 2.3 \\
Triatoma infestans & 162,136 & 92,551 & 8,079 & 8.7 \\
Panstrongylus megistus & 149,248 & 114,155 & 3,988 & 3.5 \\
Triatoma pseudomaculata & 125,634 & 85,950 & 1,481 & 1.7 \\
Triatoma brasiliensis & 99,845 & 57,983 & 3,904 & 6.7 \\
Rhodnius nasutus & 23,375 & 21,705 & 32 & 0.1 \\
Rhodnius neglectus & 3,075 & 625 & 17 & 2.7 \\
Panstrongylus lutzi & 186 & 96 & 4 & 4.2 \\
Triatoma rubrofasciata & 73 & 70 & 0 & 0 \\
Panstrongylus geniculatus & 52 & 37 & 0 & 0 \\
Triatoma melanocephala & 52 & 38 & 2 & 0 \\
Triatoma rubrovaria & 44 & 23 & 0 & 0 \\
Panstrongylus diasi & 18 & 18 & 0 & 0 \\
Triatoma vitticeps & 13 & 5 & 0 & 0 \\
Rhodnius pictipes & 7 & 1 & 0 & 0 \\
Rhodnius brethesi & 4 & 1 & 0 & 4.2 \\
Triatoma petrochii & 1 & 470,857 & 19,729 & \\
\hline Total & 753,030 & & & 0 \\
\hline Source: GT-Prograt & & 1 & 0 & 0 \\
\hline
\end{tabular}

Source: GT-Programa de Controle da Doença de Chagas/CCDTV/DEOPE/FNS. 


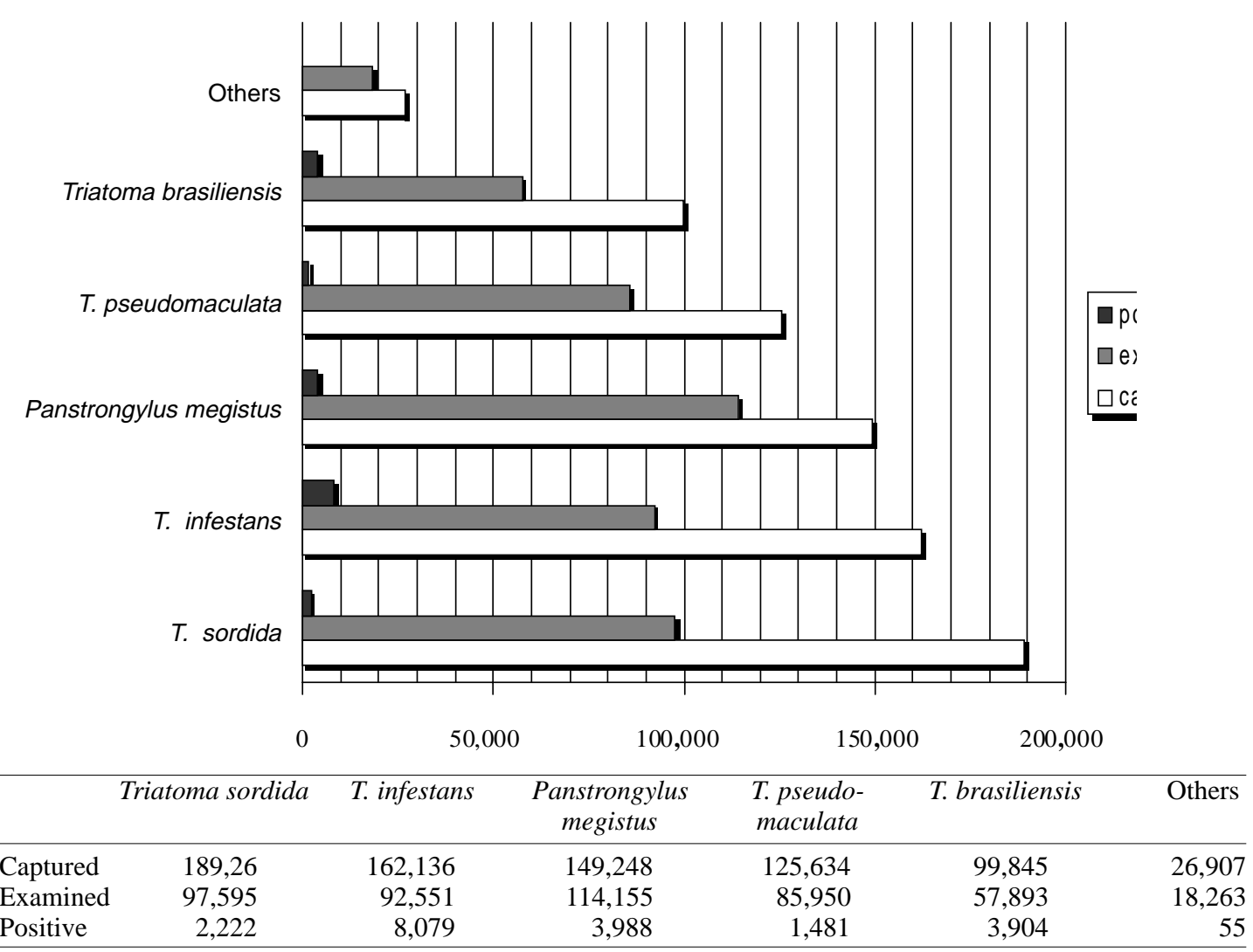

Source: GT-Programa de Controle da Doença de Chagas/CCDTV/DEOPE/FNS.

Fig. 2: triatomic survey. Species and positiveness, Brazil, 1975/1983.

"cerrado" vegetation is predominant; P. megistus is found in the more humid coastal areas, with varying degrees of domestication, and also in the inner country woods along the rivers; $T$. brasiliensis and T. pseudomaculata are native of the semi-arid northeastern region.

The chemical control of domiciled vectors did not take into consideration, at first, the "native" or "introduced" condition of the various species. As a matter of fact, the use of a standard methodology produced quite different responses. In the case of T. infestans - the most important and totally domiciled vector - it was shown that the first two spraying cycles were followed by a dramatic reduction of dispersion and infestation rates. For other species, however, there were no significant changes in dispersion rates, while intradomiciliary infestation was controlled (Silveira 1985). Furthermore, as expected, the interruption of chemical treatment was systematically followed by recolonization of native species, at intervals depending on the density of the vector in the wilderness, the receptivity of artificial ecotopes in the area and the availability of food supply. With re- gard to natural infection, continued chemical treatment often resulted in progressive exhaustion of infected colonies.

As elimination of T. infestans progressed, transmission decreased in areas where this vector had been present. However, the interruption of transmission by other vectors depended upon sustained domiciliary chemical treatment. P. megistus showed a peculiar behavior, similar to T. infestans, in northeastern "zona da mata", but in other areas it remained restricted to the wilderness, with rare adult specimens being found in households.

The following data exemplify these different situations: (1) the initial area of dispersion of $T$. infestans in the country (1975/1983) corresponded to 711 counties in 12 states. The present area (1997) comprises 105 counties in 7 states (note: lots of new counties were created during this period) (Fig. $3)$; (2) the number of T. infestans specimens captured in 1983, when the preliminary entomological evaluations were concluded, added up to 162,136 . This corresponded to $13.5 \%$ of the total number of triatomas captured, all species considered; and in 1997, the 1,080 identified specimens 

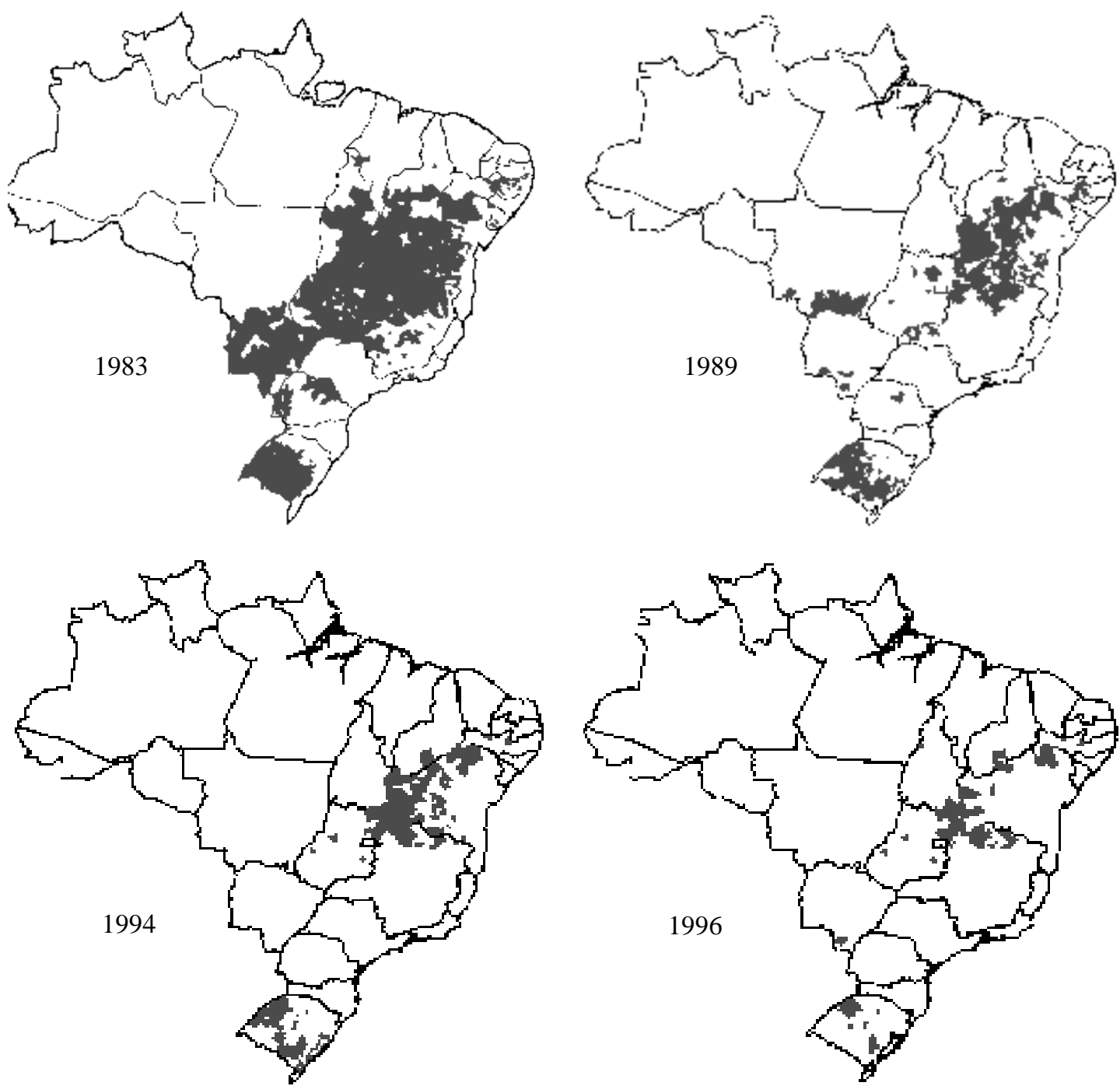

Source: GT-Programa de Controle da Doença de Chagas/CCDTV/DEOPE/FNS.

Fig. 3: infested areas by Triatoma infestans, Brazil, 1983/1996.

of $T$. infestans referred to only $0.5 \%$ of all specimens collected; (3) there was a $99.3 \%$ reduction in the number of T. infestans specimens captured during this period (from 162,136 to 1,080). Figures for other species show a $56.6 \%$ reduction for $T$. sordida (from 189,260 to 81,970); $44.4 \%$ for $T$. brasiliensis (from 99,845 to 55,513); and 61.6\% for T. pseudomaculata (from 125,634 to 48,145) (it is important to mention that although the investigation covered different areas, those containing T. infestans were privileged, given the priority to the control of this specie) (Table II); (4) the domiciled populations of $P$. megistus also dropped dramatically, from 149,248 collected specimens in 1983 to only 4,104 in 1997 . This is equivalent to a 97.2\% reduction (Table II); (5) at present $T$. infestans is not anymore the predominant specie, in any of the 18 states undergoing regular control operations.

\section{TABLE II}

Number of the major species of Triatominae captured and percentage of reduction, Brazil, 1983 and 1997

\begin{tabular}{lrrr}
\hline Species & \multicolumn{2}{c}{ Year } & \\
\cline { 2 - 3 } & \multicolumn{1}{c}{1983} & 1997 & $\%$ \\
\hline Triatoma infestans & 162,136 & 1,080 & -99.3 \\
Panstongylus megistus & 149,248 & 4,104 & -97.2 \\
Triatoma pseudomaculata & 125,634 & 48,145 & -61.6 \\
Triatoma sordida & 189,260 & 81,970 & -56.6 \\
Triatoma brasiliensis & 99,845 & 55,513 & -44.4 \\
\hline
\end{tabular}

Source: GT-Programa de Controle da Doença de Chagas/ CCDTV/DEOPE/FNS. 
On the basis of these results, it was necessary to set up new objectives, goals and operational indicators, taking into consideration the behavioral differences and other characteristics of the vector species involved in the transmission.

T. infestans is targeted for complete elimination, and that has been proven possible. Therefore, the discovery of a single specimen, in any state, in any artificial ecotope, is sufficient to justify intervention. For other species, justification for house treatment measures depends on the proven existence of intradomiciliary colonies. The control of transmission can be achieved with reduced operational efforts, by spacing the spraying cycles and thus increasing the cost effectiveness of the program (Silveira \& Rezende 1994, Ministério da Saúde 1994). Since the resources for extensive house improvement projects are limited, they must be focused on areas persistently infested by native species, specially those showing high densities of T. brasiliensis, such as parts of the northeastearn region. Besides that, and assuming house improvement projects as a means of promoting better living conditions, the available resources should be concentrated in rural northeastern areas, where the situation is particularly critical.

The impact on the vectorial transmission of Chagas disease in Brazil is demonstrated not only by entomological indicators used for monitoring control actions, but also by the absence of younger groups of people infected by T. infestans. Serological surveys carried out from 1989 to 1997 in school children aged 7 to 14 , involving the analysis of 225,000 samples from 842 counties, showed average prevalence rates around $0.14 \%$ (Table III).

The downward trend is confirmed by morbidity data based on hospitalized patients in the public sector during the present decade, which show a steady decline in the number of chronic cases of Chagas disease (Fig. 4). Acute cases have nearly desappeared from areas formaly known as hiperendemic, which also demonstrate the great impact on the transmission in the country.

Although decreases in mortality rates are difficult to demonstrate, due to the chronic evolution of the disease, preliminary analysis indicate that the number of deaths attributed to Chagas disease has dropped from 5 per 100,000 inhabitants in the early 80's to 3,5 in recent years (Fig. 5).

Many other variables may have influenced, in different ways, the entomological or serological indicators, as well as the morbidity and mortality rates. These include changes in the environment, the progressive concentration of population in urban areas, changes in the quality or accuracy in diagnostic and therapeutics procedures. There is also enough evidence indicating that the vector control initiative produced a major change. Furthermore, there is no doubt that much progress has been made in the past two decades regarding the elimination of Chagas disease in the country. The

TABLE III

Sorological survey in school population (7 to 14 years old), Brazil, 1989/1997

\begin{tabular}{|c|c|c|c|c|c|}
\hline \multirow[t]{2}{*}{ States } & \multirow{2}{*}{$\begin{array}{c}\text { No. of } \\
\text { counties }\end{array}$} & \multicolumn{3}{|c|}{ No. of samples } & \multirow[b]{2}{*}{$\%$} \\
\hline & & Collected & Examined & Positive & \\
\hline Alagoas (1990/96) & 15 & 7,335 & 7,335 & 0 & 0.00 \\
\hline Bahia ( 1994/97) & 81 & 27,804 & 26,657 & 7 & 0.03 \\
\hline Ceará (1991/95) & 33 & 38,429 & 38,429 & 9 & 0.02 \\
\hline Distrito Federal & 0 & 0 & 0 & 0 & 0.00 \\
\hline Espírito Santo & 0 & 0 & 0 & 0 & 0.00 \\
\hline Goiás (1994/97) & 161 & 15,791 & 12,584 & 57 & 0.45 \\
\hline Maranhão (1994) & 2 & 1,025 & 1,025 & 0 & 0.00 \\
\hline Mato Grosso (1995/97) & 14 & 14,138 & 14,138 & 0 & 0.00 \\
\hline Mato G. do Sul (1994/97) & 35 & 4,554 & 3,891 & 2 & 0.05 \\
\hline Minas Gerais (1989/97) & 130 & 31,448 & 29,738 & 21 & 0.07 \\
\hline Paraíba $(1993 / 95)$ & 52 & 21,769 & 21,769 & 35 & 0.16 \\
\hline Paraná (1994/96) & 72 & 22,903 & 22,903 & 7 & 0.03 \\
\hline Pernambuco (1995/97) & 7 & 1,864 & 1,864 & 1 & 0.05 \\
\hline Piauí (1996/97) & 14 & 4,939 & 4,939 & 2 & 0.04 \\
\hline Rio G. do Norte (1993/97) & 116 & 12,583 & 12,583 & 25 & 0.20 \\
\hline Rio G. do Sul (1995) & 92 & 20,857 & 20,857 & 145 & 0.70 \\
\hline Sergipe $(1995 / 97)$ & 18 & 7,426 & 7,426 & 14 & 0.19 \\
\hline Tocantins & 0 & 0 & 0 & 0 & 0.00 \\
\hline Total & 842 & 232,865 & 226,138 & 325 & 0.14 \\
\hline
\end{tabular}

Source: GT-Programa de Controle da Doença de Chagas/CCDTV/DEOPE/FNS. 


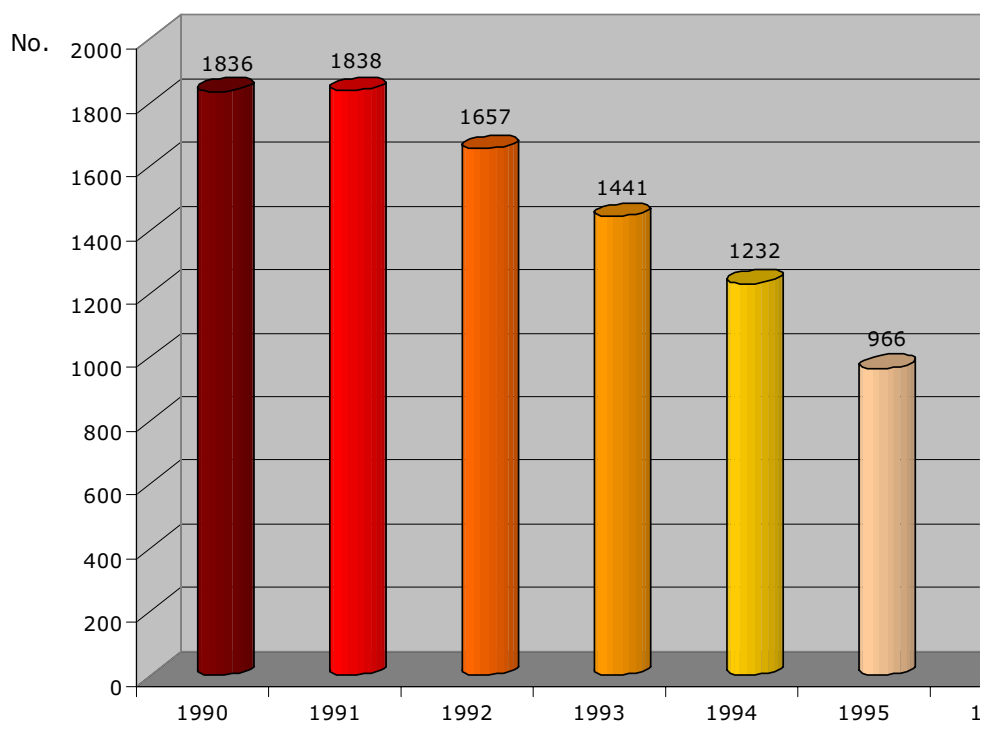

Source: GT-Programa de Controle da Doença de Chagas/CCDTV/DEOPE/FNS.

Fig. 4: number of cases of chronic Chagas disease, Brazil, 1990/1997.

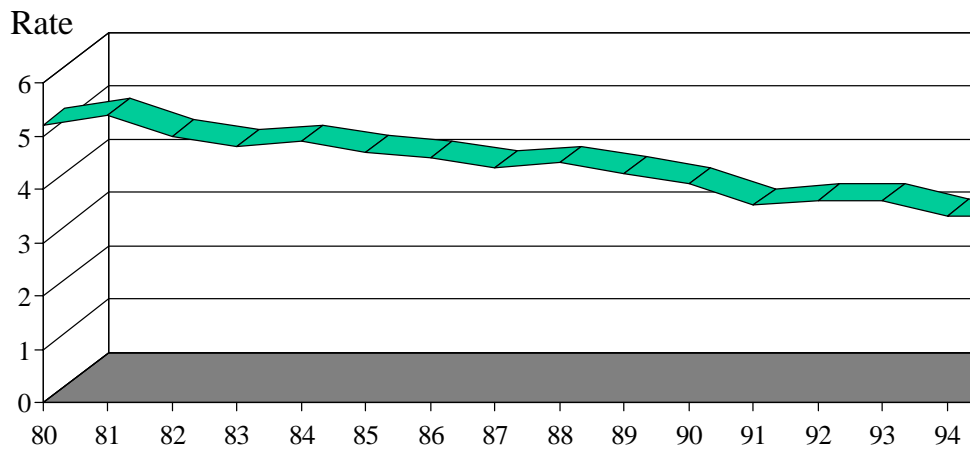

Source: GT-Programa de Controle da Doença de Chagas/CCDTV/DEOPE/FNS.

Fig. 5: Chagas disease mortality rate/100,000 inhabitants, Brazil, 1980/1996.

demonstration of such results has been decisive for other countries in the Americas to join a continental initiative, which has achieved better results in the Southern Cone, at this moment.

The elimination target means, however, that some actions have to be maintained. In the particular case of vector-borne transmission of Chagas disease, houses must be prevented from being reinfested and recolonized. Continued efforts are required, at least while the risk conditions are present, and they must be supported by horizontal actions of entomological surveillance, with effective community participation and involvement of the local health services (Dias 1993, Garcia-Zapata \& Marsden 1994, Teixeira \& Silveira 1994).
This is the present challenge: to sustain achieved control levels and to keep ongoing actions, in the absence of the disease and even in the absence of the vector.

\section{REFERENCES}

Busvine JR, Barnes S 1947. Observations on mortality among insects exposed to dry insecticidal films. Bul Entom Res 38: 80-81.

Camargo ME, Silva GR, Castilho EA, Silveira AC 1984. Inquérito sorológico de prevalência da infecção chagásica no Brasil. 1975/1980. Rev Inst Med Trop São Paulo 26: 192-204.

Dias E, Pellegrino J 1948. Alguns ensaios com o "Gamexanne" no combate aos transmisssores da doença de Chagas. Brazil Médico 62: 185-190. 
Dias JCP 1993.Vigilância epidemiológica contra o Triatoma infestans. Rev Soc Bras Med Trop 26: 39-44.

Garcia-Zapata MT, Marsden PD 1994. Enfermedad de Chagas: control y vigilancia con insecticidas y participación comunitária en Mambaí, Goiás, Brasil. Bol Ofic Sanit Panam 116: 97-110.

Ministério da Saúde, Fundação Nacional de Saúde 1994. Controle da Doença de Chagas-Diretrizes Técnicas, Fundação Nacional de Saúde, Brasília, 80 pp.

Romaña C, Abalos JW 1948. Acción del "Gamexanne" sobre los triatomídeos. Control domiciliário. An Inst Med Reg Tucumán 2: 95-106.

Silveira AC 1985. Respostas às ações de controle da doença de Chagas para espécies de triatomíneos mais e menos adaptadas ao domicílio. Nativas e introduzidas, p. 37-38. In Resumos do XXI Congresso da Sociedade Brasileira de Medicina Tropical, São Paulo.

Silveira AC, Rezende DF 1994. Epidemiologia e controle da transmissão vetorial da doença de Chagas no Brasil. Rev Soc Bras Med Trop 27: 11-22.

Silveira AC, Feitosa VR, Borges R 1984. Distribuição de triatomíneos domiciliados no período 1975/1983. Brasil. Rev Bras Malariol D Trop 36: 15-312.

Tauil PL 1998. Controle de agravos à saúde: consistência entre objetivos e medidas preventivas. Iesus 7: 5558.

Teixeira G, Silveira AC 1994. Doença de Chagas, p. 105115. In Guia de Vigilância Epidemiológica, Ministério da Saúde, Brasília. 
